\title{
Randomized clinical trial: pharmacokinetics and safety of multimatrix mesalamine for treatment of pediatric ulcerative colitis
}

This article was published in the following Dove Press journal:

Drug Design, Development and Therapy

4 February 2016

Number of times this article has been viewed

\author{
Carmen Cuffari' \\ David Pierce ${ }^{2}$ \\ Bartosz Korczowski ${ }^{3}$ \\ Krzysztof Fyderek ${ }^{4}$ \\ Heather Van Heusen ${ }^{5}$ \\ Stuart Hossack ${ }^{6}$ \\ Hong Wan ${ }^{5}$ \\ Alena YZ Edwards ${ }^{7}$ \\ Patrick Martin ${ }^{5}$ \\ 'Department of Pediatrics, Division \\ of Pediatric Gastroenterology \\ and Nutrition, The Johns Hopkins \\ University School of Medicine, \\ Baltimore, MD, USA; ${ }^{2}$ Shire, \\ Basingstoke, UK; ${ }^{3}$ Medical College, \\ University of Rzeszów, Rzeszów, \\ Poland; ${ }^{4}$ University Children's Hospital \\ of Cracow, Cracow, Poland; ${ }^{5}$ Shire, \\ Wayne, PA, USA; ${ }^{6}$ Covance Clinical \\ Research Unit Limited, Leeds, UK; \\ ${ }^{7}$ ICON Early Phase Services, Marlow, \\ Buckinghamshire, UK
}

Background: Limited data are available on mesalamine (5-aminosalicylic acid; 5-ASA) use in pediatric ulcerative colitis (UC).

Aim: To evaluate pharmacokinetic and safety profiles of 5-ASA and metabolite acetyl-5-ASA (Ac-5-ASA) after once-daily, oral administration of multimatrix mesalamine to children and adolescents with UC.

Methods: Participants (5-17 years of age; $18-82 \mathrm{~kg}$, stratified by weight) with UC received multimatrix mesalamine 30,60 , or $100 \mathrm{mg} / \mathrm{kg} /$ day once daily (to $4,800 \mathrm{mg} /$ day) for 7 days. Blood samples were collected pre-dose on days 5 and 6. On days 7 and 8, blood and urine samples were collected and safety was evaluated. 5-ASA and Ac-5-ASA plasma and urine concentrations were analyzed by non-compartmental methods and used to develop a population pharmacokinetic model.

Results: Fifty-two subjects (21 [30 mg/kg]; 22 [60 mg/kg]; 9 [100 mg/kg]) were randomized. On day 7, systemic exposures of 5-ASA and Ac-5-ASA exhibited a dose-proportional increase between 30 and $60 \mathrm{mg} / \mathrm{kg}$ /day cohorts. For 30,60, and $100 \mathrm{mg} / \mathrm{kg} /$ day doses, mean percentages of 5-ASA absorbed were $29.4 \%, 27.0 \%$, and $22.1 \%$, respectively. Simulated steady-state exposures and variabilities for 5-ASA and Ac-5-ASA (coefficient of variation approximately 50\% and $40 \%-45 \%$, respectively) were similar to those observed previously in adults at comparable doses. Treatment-emergent adverse events were reported by ten subjects. Events were similar among different doses and age groups with no new safety signals identified.

Conclusion: Children and adolescents with UC receiving multimatrix mesalamine demonstrated 5-ASA and Ac-5-ASA pharmacokinetic profiles similar to historical adult data. Multimatrix mesalamine was well tolerated across all dose and age groups. ClinicalTrials.gov Identifier: NCT01130844.

Keywords: ulcerative colitis, mesalamine, pharmacology

\section{Introduction}

Ulcerative colitis (UC) is a chronic inflammatory disease of the colon and rectum distinguished by cycles of remission and relapse over the life of the subject. ${ }^{1,2}$ While the incidence of UC peaks around early adulthood, onset of the disorder can occur from early childhood through adulthood. ${ }^{3} \mathrm{UC}$ is one of the more prevalent chronic diseases in children, with an incidence rate of 2.1 per 100,000 children within the United States. ${ }^{4}$

The primary goals in UC management are induction and maintenance of remission to improve subjects' health and quality of life. ${ }^{5}$ Oral 5-aminosalicylic acid (5-ASA) formulations, such as multimatrix mesalamine (Shire US Inc., Wayne, PA, USA), have proven effective in the induction and maintenance of UC remission, ${ }^{6-10}$ and are recommended first-line therapy for adults with active mild-to-moderate UC., 5 -ASAs are also commonly used as the standard of care first-line therapy in pediatric UC. However,
Correspondence: Carmen Cuffari Department of Pediatrics, Division of Pediatric Gastroenterology and Nutrition, The Johns Hopkins University School of Medicine, Brady 320, 600 North Wolfe Street, Baltimore, MD 21 287-263I, USA $\mathrm{Tel}+\mathrm{I} 4109558769$

Fax + I 410955 I464

Email ccuffari@jhmi.edu 
while studies that support 5-ASA use in adult subjects with UC are abundant, ${ }^{11}$ evidence on the efficacy and safety of 5-ASA in pediatric UC subjects is less substantial, with only a few randomized, controlled clinical studies for the induction or maintenance of remission by 5-ASA in pediatric subjects having been conducted. ${ }^{12,13}$ To date, no 5-ASA product has been licensed for maintenance of remission of UC in children.

As the first step in a program evaluating multimatrix mesalamine in pediatric UC, the primary objective of this randomized Phase I study (ClinicalTrials.gov Identifier: NCT01130844) was to assess the pharmacokinetics of 5-ASA and its major metabolite acetyl-5-ASA (Ac-5-ASA) after administration of once-daily multimatrix mesalamine at three different doses $(30,60$, or $100 \mathrm{mg} / \mathrm{kg} /$ day $)$ for 7 days in children and adolescents diagnosed with UC. Secondary objectives included examining the safety and tolerability of multimatrix mesalamine at these doses in children and adolescents with UC, and evaluating the extent of absorption of 5-ASA from multimatrix mesalamine at steady state.

\section{Methods}

\section{Study design}

This Phase I, multicenter, randomized, open-label, three-arm study was conducted in 12 sites across three countries (United States, Poland, and Slovakia). Children and adolescents (aged 5-17 years) with a diagnosis of UC were randomly assigned to receive multimatrix mesalamine 30,60 , or $100 \mathrm{mg} / \mathrm{kg}$ once daily (up to a maximum of $4,800 \mathrm{mg} /$ day) each morning for 7 days. To achieve these doses in children, smaller-sized 300 and $600 \mathrm{mg}$ tablets were developed for this study to augment the existing approved 1,200 mg multimatrix mesalamine tablet. Total daily doses for the study ranged from 900 to $4,800 \mathrm{mg} /$ day. Randomization was stratified by body weight (18-24, 25-49, and 50-82 kg); subjects weighing 18-24 kg were only randomized to 60 and $100 \mathrm{mg} / \mathrm{kg} / \mathrm{day}$ groups to avoid receiving doses less than $900 \mathrm{mg}$, and subjects weighing $50-82 \mathrm{~kg}$ were only randomized to 30 and $60 \mathrm{mg} / \mathrm{kg} / \mathrm{day}$ groups to avoid receiving doses greater than $4,800 \mathrm{mg}$, the maximum approved dose in adult subjects. Randomization was achieved via use of a randomization number allocated prior to dosing, once eligibility had been determined, and a randomization schedule was produced by an interactive voice response system vendor. Subjects were dosed with multimatrix mesalamine every morning for 7 days, at home on days 1-4, and on-site on days 5-7. On day 7, blood and urine pharmacokinetic samples were collected and safety assessments were performed until 24 hours post-dose. The study protocol, protocol amendments, informed consent documents, relevant supporting information, and subject recruitment information were submitted to and approved by the respective independent ethics committees, institutional review boards, and regulatory agencies prior to study initiation. The independent ethics committees, institutional review boards, and regulatory agencies are from the following: United States: Arkansas Children's Hospital, Advanced Clinical Research Institute, University of California, San Francisco, Connecticut Children's Medical Center, University of Maryland Medical Center for Children, and Mayo Clinic; Australia: Royal Children's Hospital Melbourne; Poland: Klinika Pediatrii Gastroenterologii i Zywienia, Uniwersytecki Szpital Dzieciecy w Krakowie, Klinika Pediatrii Dzieciecy Szpital Kliniczny im prof Antoniego Gebali, Kliniczny Oddzial Pediatrii z Pododdzialem Neurologii Dzieciecej Szpital Wojewodzki, Klinika Gastroenterolofii Pediatrii, Instytut Centrum Zdrowia Matki Polki, Oddzial Gastroenterologii i Hepatologii, and Instytut PomnikCentrum Zdrowia Dziecka; Slovakia: Gastroenterologicka ambulancia, Univerzitna nemocnica Martin, and DFNsP Banska Bystrica; and the United Kingdom: Alder Hey Children's NHS Foundation Trust, Barts Health NHS Trust/Royal London Hospital, Somers Clinical Research Facility/Great Ormond Street Hospital, Southampton General Hospital. Further details are available at https://clinicaltrials.gov/ct2/ show/NCT01130844. All authors had access to the study data, and reviewed and approved the final manuscript.

\section{Study population}

Children (aged 5-12 years) and adolescents (aged 13-17 years), weighing $18-82 \mathrm{~kg}$, with a diagnosis of $\mathrm{UC} \geq 3$ months prior to the first dose of study drug were enrolled. Subjects already on a 5-ASA product had to have been on a stable regimen for $\geq 4$ weeks prior to the first dose of study drug. In addition to each subject documenting assent, the subject's parent or legal representative had to provide informed consent. Subjects with current or recurrent disease (other than UC) that could affect the colon or the action, absorption, or disposition of the study drug were excluded. Additional exclusion criteria included: UC confined to the rectum; allergy, hypersensitivity, or poor tolerability to salicylates or aminosalicylates; history of hepatic or renal impairment, pancreatitis, or Reyes syndrome; use of another investigational product $\leq 30$ days prior to the first dose of study drug; serious, severe, or unstable psychiatric or physical illness; positive urine screen for drugs or abuse of alcohol; and pregnancy or lactation in female subjects.

\section{Pharmacokinetic evaluations}

Blood samples $(2 \mathrm{~mL})$ for the measurement of 5-ASA and Ac-5-ASA plasma concentrations were taken pre-dose on days 
5 and 6 and at the following time points on day 7: pre-dose, and 2, 4, 6, 9, 12, 16, and 24 hours after dosing. In addition, a complete 0 - to 24-hour urine collection was made for the determination of urinary excretion of 5-ASA and Ac-5-ASA, starting within 30 minutes before the morning meal on day 7 until the final void scheduled for 30 minutes before the morning meal on day 8. Plasma and urine concentrations of 5-ASA and Ac-5-ASA were determined by validated methods based on liquid chromatography with tandem mass spectrometry (LC-MS/MS). The bioanalytical methods used for the quantitation of the plasma and the urine samples were validated, and quality control and calibration standard data were accepted in accordance with the U.S. Food and Drug Administration (FDA) guidance for bioanalytical method validation. ${ }^{14}$ Pharmacokinetic parameters were determined from the plasma concentration-time data by non-compartmental analysis.

The plasma assay ranged from 5 to $5,000 \mathrm{ng} / \mathrm{mL}$ for both 5-ASA and Ac-5-ASA. In each analytical batch, two low, two mid, and two high quality control (QC) samples were analyzed along with the study samples. The QC sample concentrations of both analytes in plasma were 12.5, 2,500, and 4,000 ng/mL. The inter-day coefficient of variation (CV) values ranged from $5.0 \%$ to $7.6 \%$ for 5 -ASA and from $4.8 \%$ to $10.1 \%$ for Ac-5ASA. Accuracy (expressed as percentage of the difference of the mean value for each pool from the theoretical concentration) values ranged from $-0.8 \%$ to $1.6 \%$ for 5 -ASA and from $2.4 \%$ to $5.2 \%$ for Ac-5-ASA. In 12 out of 14 analytical batches, three dilution QC samples were analyzed along with the study samples. The dilution QC sample concentrations for both analytes in plasma were each 10,000 ng/mL, and the dilution QC samples were analyzed after a 1:5 dilution with control plasma. The inter-day CV value was 5.5\% for 5-ASA and $6.1 \%$ for Ac-5-ASA, and the accuracy values were $4.0 \%$ and $4.0 \%$, respectively. Recoveries of 5-ASA and Ac-5-ASA from plasma were shown during assay validation to be $>95 \%$.

The urine assay ranged from 5 to $1,000 \mu \mathrm{g} / \mathrm{mL}$ for both 5-ASA and Ac-5-ASA. In each analytical batch, two low, two mid, and two high QC samples were analyzed along with the study samples. The QC sample concentrations of both analytes were 15,400 , and $800 \mu \mathrm{g} / \mathrm{mL}$. The inter-day $\mathrm{CV}$ values ranged from $6.7 \%$ to $11.7 \%$ for 5 -ASA and from $7.6 \%$ to $10.2 \%$ for Ac-5-ASA. Accuracy values ranged from $-5.5 \%$ to $-1.3 \%$ for 5 -ASA and from $1.4 \%$ to $4.0 \%$ for Ac-5-ASA. In three out of nine analytical batches, three dilution QC samples were analyzed along with the study samples. The dilution QC sample concentrations for both analytes in urine were each 2,000 $\mu \mathrm{g} / \mathrm{mL}$, and the dilution QC samples were analyzed after a 1:5 dilution with control urine. The interday CV value was $7.8 \%$ for 5 -ASA and $7.2 \%$ for Ac-5-ASA, and the accuracy values were $-2.5 \%$ and $2.0 \%$, respectively. Recoveries of 5-ASA and Ac-5-ASA from urine were shown during assay validation to be $>90 \%$.

A total of 52 plasma samples and six urine samples were re-analyzed to assess incurred sample reproducibility. Results for $100 \%$ of these samples were found to be within $\pm 20 \%$ of the mean of the original and re-assay results, meeting the predefined acceptance criteria.

\section{Safety}

Safety was evaluated by reported adverse events (AEs) at each study visit and while the subject was on-site, and included assessment of clinical laboratory parameters, physical examination findings, vital signs, and 12-lead electrocardiogram. Safety analyses were performed on all randomized subjects who took $\geq 1$ dose of study drug and had $\geq 1$ post-dose safety assessment (safety analysis set). Safety data were summarized by treatment group and by treatment group stratified by age (5-12 years and 13-17 years).

\section{Sample size}

It was anticipated that up to 60 subjects would be needed for screening to enroll 45 subjects. Thirty subjects were required to complete the study and, per agreement with the FDA, a minimum of six subjects were to be assigned to each age group (5-12 years and 13-17 years), as well as a minimum of six subjects per dose level $(30,60$, and $100 \mathrm{mg} / \mathrm{kg} /$ day $)$.

\section{Non-compartmental pharmacokinetic analysis}

Pharmacokinetic parameters were determined (WinNonlin 5.2; Pharsight Corporation, Mountain View, CA, USA) for 5-ASA and Ac-5-ASA for all subjects in the safety analysis set who generated sufficient plasma samples to allow reliable determination of maximum concentration $\left(\mathrm{C}_{\max , \mathrm{ss}}\right)$ and area under the curve for the defined interval between doses $\left(\mathrm{AUC}_{\mathrm{ss}}\right.$; tau=24 h) at steady state (ie, the pharmacokinetic set). All calculations were based on actual sampling times. Pharmacokinetic parameters that were derived based on 5-ASA and/or Ac-5-ASA concentrations, as appropriate, included $\mathrm{AUC}_{\mathrm{ss}}, \mathrm{C}_{\text {max,ss }}$, time of maximum observed concentration sampled during a dosing interval $\left(\mathrm{t}_{\max }\right)$, cumulative amount recovered in urine in time interval 0-24 hours $\left(\mathrm{Xu}_{0-24 \mathrm{~h}}\right)$, clearance from the blood by the kidneys $\left(\mathrm{CL}_{\mathrm{R}}\right)$, metabolic ratio (Ac-5-ASA:5-ASA) calculated using $\mathrm{C}_{\text {max }, \mathrm{ss}}\left(\mathrm{MR}_{\mathrm{Cmax}, \mathrm{ss}}\right)$, metabolic ratio (Ac-5-ASA:5-ASA) calculated using $\mathrm{AUC}_{\mathrm{s} s}$ $\left(\mathrm{MR}_{\mathrm{AUCs}}\right)$, and percentage of the dose absorbed, calculated as:

$\begin{aligned} & \% \text { of dose } \\ & \text { absorbed }\end{aligned}=\frac{\left(\mathrm{Xu}_{0-24 \mathrm{~h}} 5-\mathrm{ASA}+\left[0.7847 \times \mathrm{Xu}_{0-24 \mathrm{~h}} \mathrm{Ac}-5-\mathrm{ASA}\right]\right)}{\text { Dose }} \times 100$ 
where 0.7847 is the ratio of the molecular weight of 5-ASA (153.14) to the molecular weight of Ac-5-ASA (195.15).

AUC values were calculated using the linear trapezoidal method when concentrations were increasing, and the logarithmic trapezoidal method when concentrations were decreasing. No inferential statistical analyses were conducted on the pharmacokinetic data. Summary statistics were presented by treatment group and by treatment group stratified by age (5-12 years, 13-17 years) for all pharmacokinetic parameters. Achievement of steady state was assessed by visual inspection of pre-dose plasma concentrations on days 5, 6, and 7. Systemic exposure $\left(\mathrm{C}_{\text {max,ss }}\right.$ and $\left.\mathrm{AUC}_{\mathrm{ss}}\right)$ was assessed by comparison with historical data in healthy adult subjects administered multimatrix mesalamine 2,400 or $4,800 \mathrm{mg} /$ day. ${ }^{15,16}$

\section{Population pharmacokinetic analysis}

A population pharmacokinetic model was developed using non-linear mixed effects modeling (NONMEM ${ }^{\circledR}$ program, Version 7.2.0; ICON, Ellicott City, MD, USA) to describe the population variability in 5-ASA/Ac-5-ASA pharmacokinetics and the relationship between pharmacokinetic parameters and potential explanatory covariates (eg, age, weight, and sex). Pharmacokinetic parameters were estimated using Monte-Carlo Importance Sampling Expectation Maximization method with "Mu Referencing". ${ }^{17}$ Development of the population pharmacokinetic model consisted of building a base model, followed by development of a covariate model using an interim data cut (40 subjects); the final model was updated with data from an additional 12 subjects from the study. Structural model selection was data driven, based on goodness-of-fit plots (observed vs predicted concentration, conditional weighted residual vs predicted concentration or time, histograms of individual random effects, etc), successful convergence, plausibility and precision of parameter estimates, and the minimum objective function value. Missing drug concentrations and concentrations reported as "not quantifiable" were excluded in the analysis. The final pharmacokinetic model was evaluated using visual predictive check (VPC), and this model was used to simulate the expected 5-ASA and Ac-5-ASA plasma concentration profiles in a broader population of children and adolescents using Trial Simulator (Version 2.2.1, Pharsight Corporation). Data presentation and construction of plots were performed using S-PLUS (Version 8.1; Tibco Software Inc., Palo Alto, CA, USA). The simulated exposures were compared to historical adult exposures. ${ }^{15,16}$

\section{Results \\ Subjects}

Between October 2010 and June 2013, a total of 52 subjects were screened, randomized, and treated; all completed the study ( 21 subjects [ 5 children, 16 adolescents] in the $30 \mathrm{mg} / \mathrm{kg} /$ day dose group, 22 [4 children, 18 adolescents] in the $60 \mathrm{mg} / \mathrm{kg} /$ day dose group, and 9 [ 7 children, 2 adolescents] in the $100 \mathrm{mg} / \mathrm{kg} /$ day dose group; Figure 1). While the study met the FDA enrollment requirement of a minimum of six subjects per dose level, more patients were enrolled into the 30 and $60 \mathrm{mg} / \mathrm{kg} /$ day dose groups than into the $100 \mathrm{mg} / \mathrm{kg} /$ day dose group due to difficulties enrolling children who weighed $<49 \mathrm{~kg}$. Overall, demographic data and baseline disease characteristics were well balanced between dose groups, although fewer subjects were studied in the $100 \mathrm{mg} / \mathrm{kg} /$ day dose group due to enrollment difficulties (Table 1).

\section{Non-compartmental pharmacokinetics}

Inter-assay accuracy and precision data for 5-ASA and Ac-5ASA in the QC samples at three concentrations each in human plasma and urine across all analytical batches are shown in Table S1. For 5-ASA, mean plasma concentration-time profiles attained maxima at $\sim 6$ or 9 hours post-dose, with a secondary peak at 24 hours post-dose (Figure 2A; Table 2). Median $\mathrm{t}_{\max }$ was 6 and 9 hours (range 0-24 hours for all dose levels) post-dose for 30 and $60 \mathrm{mg} / \mathrm{kg} /$ day doses, respectively. For $100 \mathrm{mg} / \mathrm{kg} /$ day, median $\mathrm{t}_{\max }$ was approximately 2 hours post-dose; however, there were only nine subjects

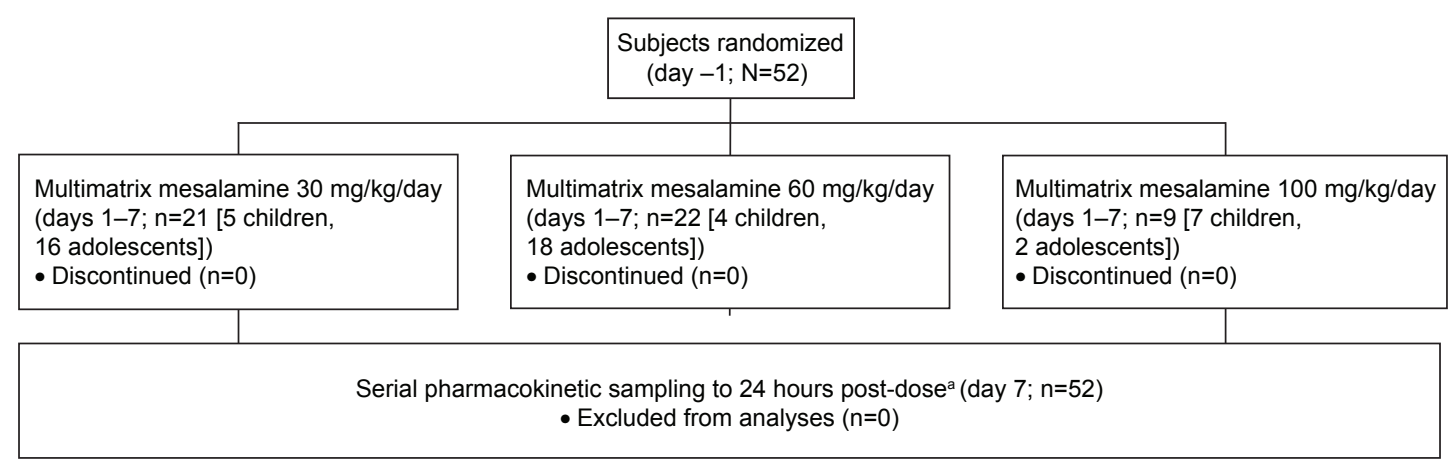

Figure I Subject flow diagram.

Note: ancluded blood and urine collection. 
Table I Demographic data and baseline characteristics

\begin{tabular}{|c|c|c|c|c|}
\hline & \multicolumn{4}{|c|}{ Multimatrix mesalamine } \\
\hline & $30 \mathrm{mg} / \mathrm{kg} / \mathrm{day}, \mathrm{n}=21$ & $60 \mathrm{mg} / \mathrm{kg} / \mathrm{day}, \mathrm{n}=22$ & $100 \mathrm{mg} / \mathrm{kg} / \mathrm{day}, \mathrm{n}=9$ & All doses, $\mathrm{N}=52$ \\
\hline Mean age (SD), years & $14.0(2.88)$ & $13.9(2.59)$ & $10.6(3.28)$ & I3.3 (3.06) \\
\hline \multicolumn{5}{|l|}{ Sex, n (\%) } \\
\hline Male & $7(33.3)$ & II (50.0) & $4(44.4)$ & $22(42.3)$ \\
\hline Female & $14(66.7)$ & II (50.0) & $5(55.6)$ & $30(57.7)$ \\
\hline \multicolumn{5}{|l|}{ Ethnicity, n (\%) } \\
\hline Not Hispanic or Latino & $21(100.0)$ & $21(95.5)$ & $9(100.0)$ & $51(98.1)$ \\
\hline Hispanic or Latino & 0 & $\mathrm{I}(4.5)$ & 0 & $\mathrm{I}(\mathrm{I} .9)$ \\
\hline \multicolumn{5}{|l|}{ Race, n (\%) } \\
\hline White & $20(95.2)$ & $22(100.0)$ & $9(100.0)$ & $51(98.1)$ \\
\hline Asian & I (4.8) & 0 & 0 & $I(1.9)$ \\
\hline Mean BMI (SD), ${ }^{a} \mathrm{~kg} / \mathrm{m}^{2}$ & $20.71(3.365)$ & $19.16(3.123)$ & $17.15(2.330)$ & $19.44(3.308)$ \\
\hline \multicolumn{5}{|l|}{ BMI category, ${ }^{\mathrm{b}} \mathrm{n}(\%)$} \\
\hline Healthy weight & $17(81.0)$ & $19(86.4)$ & $9(100.0)$ & $45(86.5)$ \\
\hline Obese & $2(9.5)$ & I (4.5) & 0 & $3(5.8)$ \\
\hline Overweight & $2(9.5)$ & 0 & 0 & $2(3.8)$ \\
\hline Underweight & 0 & $2(9.1)$ & 0 & $2(3.8)$ \\
\hline $\begin{array}{l}\text { Median time since diagnosis } \\
\text { of UC (range), }{ }^{c} \text { years }\end{array}$ & $2.14(0.3-9.4)$ & $2.24(0.2-9.6)$ & $1.66(0.3-8.2)$ & I.83 (0.2-9.6) \\
\hline
\end{tabular}

Notes: a Calculated as screening weight $(\mathrm{kg}) /$ height $\left(\mathrm{m}^{2}\right)$. ${ }^{\mathrm{b}}$ Categories derived using the CDC BMI percentiles for children and adolescents: underweight $=$ BMI $<5$ th percentile; healthy weight $=$ BMI 5 th percentile to $<85$ th percentile; overweight $=$ BMI 85 th percentile to $<95$ th percentile; obese $=$ BMI $\geq 95$ th percentile. ${ }^{~}$ Calculated as "date of diagnosis - date of first dose/365.25".

Abbreviations: BMI, body mass index; CDC, Centers for Disease Control and Prevention; SD, standard deviation; UC, ulcerative colitis.
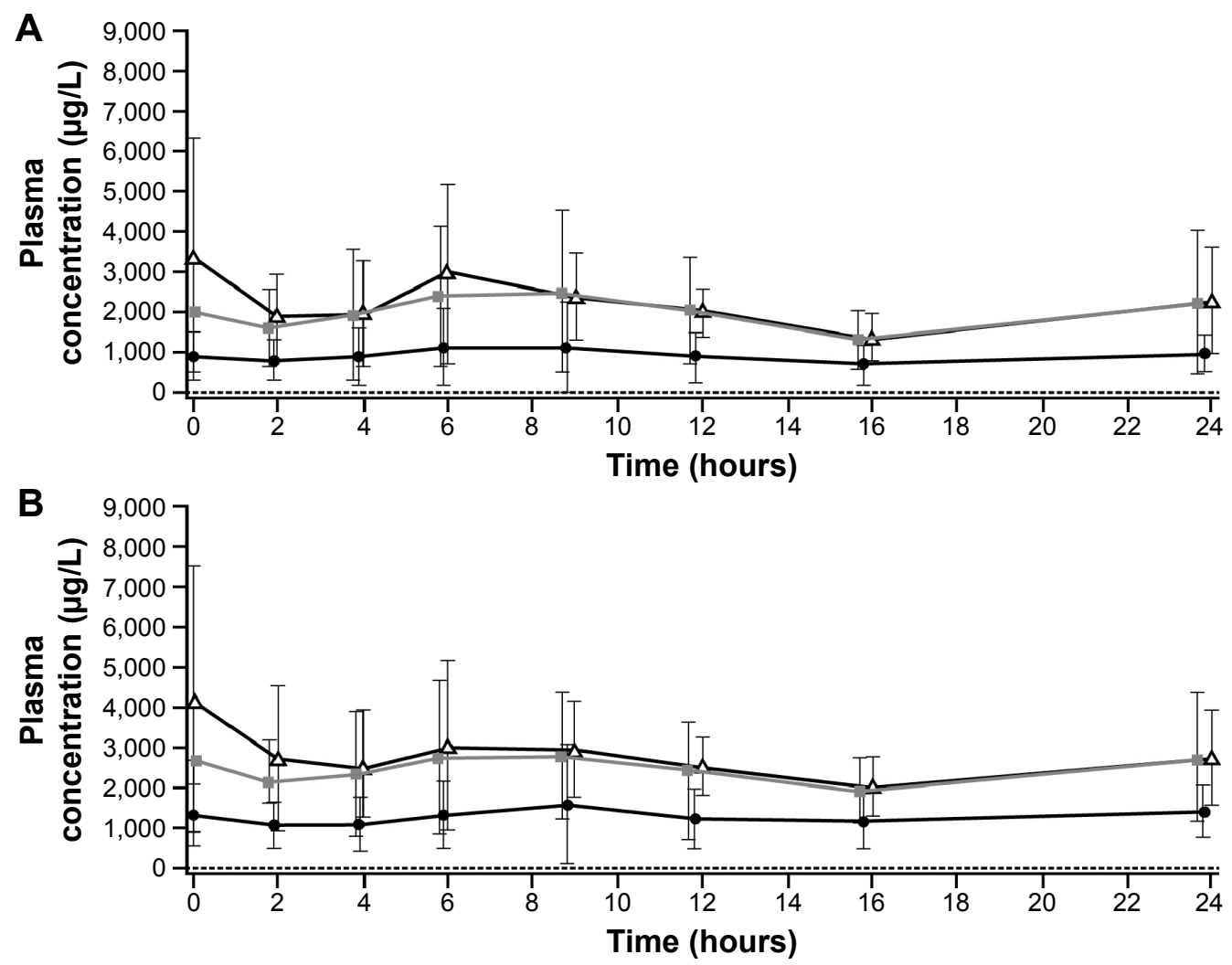

$30 \mathrm{mg} / \mathrm{kg} / \mathrm{day}$ multimatrix mesalamine
$60 \mathrm{mg} / \mathrm{kg} /$ day multimatrix $\triangle 100 \mathrm{mg} / \mathrm{kg} /$ day multimatrix mesalamine mesalamine

Figure 2 Mean (SD) plasma concentration-time profiles for (A) 5-ASA and (B) Ac-5-ASA in children and adolescents by treatment group. Abbreviations: 5-ASA, 5-aminosalicylic acid; Ac-5-ASA, acetyl-5-aminosalicylic acid; SD, standard deviation. 
Table 2 Summary of pharmacokinetic parameters of 5-ASA and Ac-5-ASA in children and adolescents

\begin{tabular}{|c|c|c|c|}
\hline & \multicolumn{3}{|c|}{ Multimatrix mesalamine } \\
\hline & $30 \mathrm{mg} / \mathrm{kg} / \mathrm{day}, \mathrm{n}=21$ & $60 \mathrm{mg} / \mathrm{kg} / \mathrm{day}, \mathrm{n}=22$ & $100 \mathrm{mg} / \mathrm{kg} / \mathrm{day}, \mathrm{n}=9$ \\
\hline \multicolumn{4}{|l|}{ 5-ASA } \\
\hline $\mathrm{AUC}_{\mathrm{ss}}(\mu \mathrm{g} \times \mathrm{h} / \mathrm{L})$, mean $(\mathrm{SD})$ & $2 I, 4 I I(I I, 08 I)$ & $46,173(22,864)$ & $49,213(17,664)$ \\
\hline $\mathrm{C}_{\text {max } x s}(\mu g / L)$, mean $(S D)$ & $1,884(1,018)$ & $3,825(1,979)$ & $4,314(2,602)$ \\
\hline $\mathrm{t}_{\max }(\mathrm{h})$, median (min, max) & $6.00(0.00,24.0)$ & $8.98(0.00,24.0)$ & $1.98(0.00,24.0)$ \\
\hline $\mathrm{Xu}_{0-24 \mathrm{~h}}(\mathrm{mg})$, mean $(\mathrm{SD})$ & $162(132)$ & $298(221)$ & $235(12 I)$ \\
\hline $\mathrm{CL}_{\mathrm{R}}(\mathrm{L} / \mathrm{h})$, mean $(\mathrm{SD})$ & $6.48(2.99)$ & $5.94(2.95)$ & $4.95(2.07)$ \\
\hline$\%$ dose absorbed, mean (SD) & $29.4^{a}(14.5)$ & $27.0(13.5)$ & $22.1(13.6)$ \\
\hline \multicolumn{4}{|l|}{ Ac-5-ASA } \\
\hline $\mathrm{AUC}_{\mathrm{ss}}(\mu \mathrm{g} \times \mathrm{h} / \mathrm{L})$, mean $(\mathrm{SD})$ & $30,942(13,743)$ & $58,119(22,729)$ & $63,067(21,752)$ \\
\hline $\mathrm{C}_{\max , \mathrm{ss}}(\mu \mathrm{g} / \mathrm{L})$, mean $(\mathrm{SD})$ & $2,396(1,217)$ & $4, I I 3(I, 64 I)$ & $4,968(2,911)$ \\
\hline $\mathrm{t}_{\max }(\mathrm{h})$, median $(\min , \max )$ & $9.00(0.00,24.0)$ & $7.48(0.00,24.0)$ & $1.98(0.00,24.0)$ \\
\hline $\mathrm{Xu}_{0-24 \mathrm{~h}}(\mathrm{mg})$, mean $(\mathrm{SD})$ & $532(4 I I)$ & $708(34 I)$ & $593(25 \mathrm{I})$ \\
\hline $\mathrm{CL}_{\mathrm{R}}(\mathrm{L} / \mathrm{h})$, mean $(\mathrm{SD})$ & $16.2(6.72)$ & $12.2(4.43)$ & $10.0(4.36)$ \\
\hline $\mathrm{MR}_{\mathrm{AUCss}}$, mean (SD) & $1.56(0.422)$ & $1.34(0.244)$ & $1.31(0.219)$ \\
\hline$M R_{C \max , s s}$, mean $(S D)$ & $1.37(0.409)$ & $1.15(0.247)$ & $1.18(0.223)$ \\
\hline
\end{tabular}

Notes: ${ }^{a} \mathrm{n}=20$; exclusion of outlier from summary statistics.

Abbreviations: 5-ASA, 5-aminosalicylic acid; Ac-5-ASA, acetyl-5-aminosalicylic acid; AUC , area under the curve for the defined interval between doses (tau = 24 h); SD, standard deviation; $C_{\operatorname{maxss}}$, maximum concentration occurring at $t_{\max } ; t_{\max }$, time of maximum observed concentration sampled during a dosing interval; $\mathrm{Xu}_{0-24 \mathrm{~h}}$, cumulative amount recovered in urine in the time interval 0-24 hours; $C_{R}$, clearance of a substance from the blood by the kidneys; $M R_{A U C s s}$, metabolic ratio (Ac-5-ASA:5-ASA) calculated using the $\mathrm{AUC}_{\mathrm{ss}}$; $\mathrm{MR}_{\mathrm{Cmax}_{\mathrm{s}} \mathrm{s}}$, metabolic ratio (Ac-5-ASA:5-ASA) calculated using the $\mathrm{C}_{\text {max,ss }}$; min, minimum; max, maximum.

at $100 \mathrm{mg} / \mathrm{kg} /$ day. Steady-state plasma concentrations for 5-ASA were attained by day 5 for all doses. On day 7 , systemic exposure to 5-ASA (mean $\mathrm{AUC}_{\mathrm{ss}}$ and $\mathrm{C}_{\text {max }, \mathrm{ss}}$ ) increased in a dose-proportional manner between 30 and $60 \mathrm{mg} / \mathrm{kg} /$ day doses, but in a subproportional manner between 60 and $100 \mathrm{mg} / \mathrm{kg} /$ day doses. Based on urinary recovery, the mean percentages of 5-ASA absorbed from multimatrix mesalamine were $29.4 \%, 27.0 \%$, and $22.1 \%$ for 30,60 , and $100 \mathrm{mg} / \mathrm{kg} /$ day doses, respectively. High between-subject variability was noted for 5-ASA $\mathrm{AUC}_{\mathrm{ss}}$ and $\mathrm{C}_{\text {max }, \mathrm{ss}}$, with arithmetic $\mathrm{CV}$ values ranging from $36 \%$ to $52 \%$ and $52 \%$ to $60 \%$, respectively. Mean $\mathrm{CL}_{\mathrm{R}}$ ranged from 5.0 to $6.5 \mathrm{~L} / \mathrm{h}$, with a trend toward decreasing with increasing dose.

Mean plasma concentration-time profiles of plasma Ac-5-ASA were similar to those of the parent drug 5-ASA (Figure 2B; Table 2), with median $\mathrm{t}_{\max }$ of 9, 7.5, and 2 hours post-dose for 30,60 , and $100 \mathrm{mg} / \mathrm{kg} /$ day doses, respectively. Steady-state plasma concentrations for Ac-5-ASA were attained by day 5 for all doses. On day 7, as for 5-ASA, systemic exposure to Ac-5-ASA increased in a dose-proportional manner between 30 and $60 \mathrm{mg} / \mathrm{kg} /$ day doses, but in a subproportional manner between 60 and $100 \mathrm{mg} / \mathrm{kg} /$ day doses. The metabolite Ac-5-ASA was more abundant than the parent drug (Table 2; $\mathrm{MR}_{\mathrm{AUCss}}$ of Ac-5-ASA:5-ASA), with no apparent trend across dose. Mean $\mathrm{CL}_{\mathrm{R}}$ ranged from 10.0 to $16.2 \mathrm{~L} / \mathrm{h}$, with a trend toward decreasing with increasing dose. Moderate to high between-subject variability was noted for $\mathrm{AUC}_{\mathrm{ss}}$ and $\mathrm{C}_{\text {max,ss }}$, with arithmetic $\mathrm{CV}$ values ranging from $35 \%$ to $44 \%$ and $40 \%$ to $59 \%$, respectively. There was no apparent difference in 5-ASA or Ac-5-ASA systemic exposure, as measured by mean $\mathrm{AUC}_{\mathrm{ss}}$ and $\mathrm{C}_{\text {max,ss }}$, between children (aged 5-12 years) and adolescents (aged 13-17 years) for this weight-based dosing paradigm (data not shown).

\section{Population pharmacokinetics}

The pharmacokinetics of 5-ASA and Ac-5-ASA were adequately described by the population pharmacokinetic structural model (Figure S1) that included: first-order absorption from two depot compartments, absorption lag times, and separate central compartments for 5-ASA and Ac-5-ASA with respective urine compartments for renal clearance. Non-renal clearance of 5-ASA was assumed to involve only metabolism to Ac-5-ASA, and all elimination processes were based on the first-order kinetics. Allometric scaling by body weight was applied to all clearance and volume parameters, with the exponents fixed to the theoretical value of 0.75 for clearance and 1 for volume parameters. ${ }^{18}$ Parameter estimates for the final model are shown in Table S2; following evaluation by VPC, less than $9 \%$ of the observed concentrations fell outside the $90 \%$ prediction intervals for both analytes, suggesting that the final model adequately described the observed data. For a $70 \mathrm{~kg}$ individual, the typical value of 5-ASA apparent renal clearance was estimated to be $1.15 \mathrm{~L} / \mathrm{h}$ (95\% confidence interval [CI]: 1.01-1.32 L/h), and apparent metabolic clearance was estimated to be $85.6 \mathrm{~L} / \mathrm{h}(95 \% \mathrm{CI}$ : 75.9-96.5 L/h). The typical value of Ac-5-ASA apparent renal clearance was estimated to be $2.54 \mathrm{~L} / \mathrm{h}$ (95\% CI: $2.27-$ $2.86 \mathrm{~L} / \mathrm{h}$ ), and apparent non-renal clearance was estimated 
to be $74.4 \mathrm{~L} / \mathrm{h}(95 \% \mathrm{CI}: 66.7-83.1 \mathrm{~L} / \mathrm{h})$. Typical estimates of the central volume of distribution were $109 \mathrm{~L}$ (95\% CI: 70.1-169 L) for 5-ASA and 7.10 L (95\% CI: 5.31-9.49 L) for Ac-5-ASA. Estimated absorption rates from depot 1 and depot 3 were $0.0334 \mathrm{~h}^{-1}$ (95\% CI: 0.0207-0.0539 $\mathrm{h}^{-1}$ ) and $0.273 \mathrm{~h}^{-1}$ (95\% CI: $\left.0.165-0.448 \mathrm{~h}^{-1}\right)$. Corresponding estimated absorption lag times from each depot were 5.10 hours (95\% CI: $4.31-6.05$ hours) and 15.0 hours (95\% CI: 14.0-16.1 hours); the lag time from depot 3 represented the additional lag following delay in absorption from depot 1 . The fraction of dose absorbed from depot 1 was estimated to be 0.734 (95\% CI: 0.413-1.06), and remaining dose fractions were assumed to be absorbed from depot 3. Goodness-of-fit plots for 5-ASA and Ac-5-ASA plasma concentrations are shown in Figures $\mathrm{S} 2$ and $\mathrm{S} 3$.

The population pharmacokinetic model was used to simulate steady-state profiles for both 5-ASA and Ac-5-ASA for four weight groups (18-23, 24-35, 36-50, and 51-90 kg) at planned high doses $(1,800,2,400,3,600$, and 4,800 mg) and low doses $(900,1,200,1,800$, and 2,400 mg) in 80 subjects with 1,000 replications (Figure 3A-D; Tables S3 and S4). The variability in the predicted steady-state exposures for children and adolescents was approximately 50\% (CV\%) for 5-ASA AUC (Table S3) and 40\%-45\% for Ac-5ASA AUC (Table S4). The proposed low dose of multimatrix mesalamine for each weight category is predicted to provide
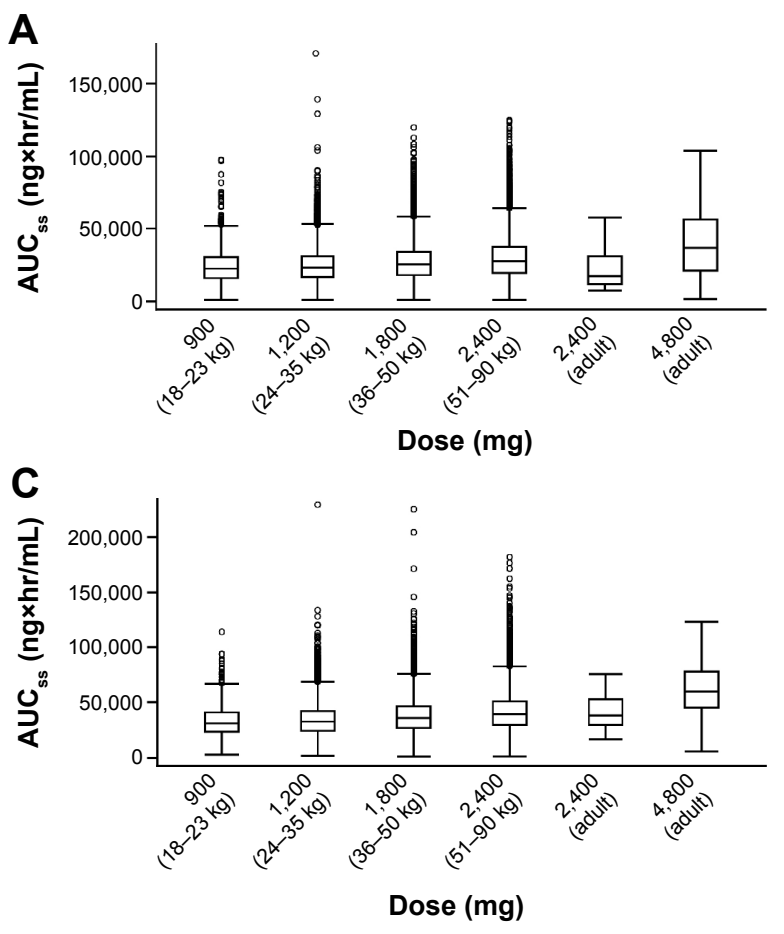

comparable steady-state exposure for both 5-ASA and Ac-5 -ASA to those observed following administration of a fixed 2,400 $\mathrm{mg}$ dose in the adult population (Figure 3A-D). The proposed high dose for each weight category is predicted to provide comparable steady-state AUC for both 5-ASA and Ac-5-ASA to those observed following administration of a fixed 4,800 $\mathrm{mg}$ dose in the adult population.

\section{Safety}

The incidence of treatment-emergent adverse events (TEAEs) was $19.2 \%$ (ten subjects overall); all TEAEs were mild to moderate (Table 3 ). Incidence rates were similar among different dose groups, and the most commonly reported TEAEs were abdominal pain, musculoskeletal pain, and headache, each reported in $3.8 \%$ of subjects ( $n=2$ each). There were no TEAEs leading to premature discontinuation. Two subjects $(3.8 \%)$ experienced a TEAE considered by the investigator to be related to the study drug: one subject in the $30 \mathrm{mg} / \mathrm{kg} /$ day dose group experienced abdominal pain, dehydration, and vomiting, and one subject in the $60 \mathrm{mg} / \mathrm{kg}$ /day dose group experienced moderate upper abdominal pain. No relevant differences between the age groups were observed with regard to the occurrence, severity, or relatedness of TEAEs, and no clinically relevant abnormalities in biochemistry, hematology, urinalysis, or vital sign values were observed. No new safety signals were reported.
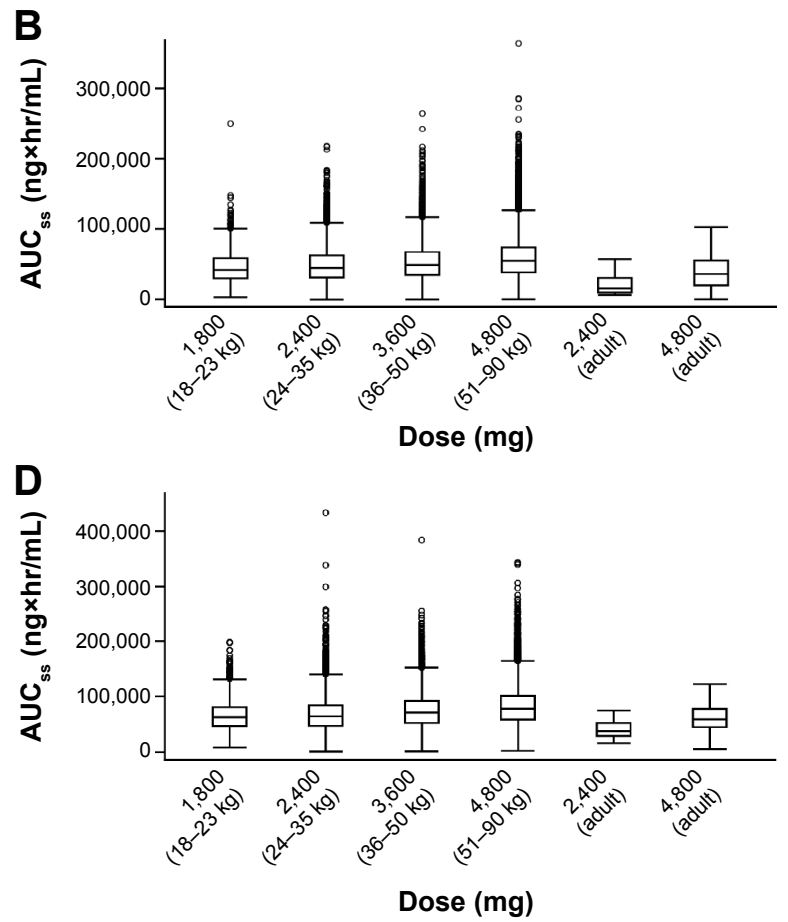

Figure 3 Box and whisker plots of simulated 5-ASA and Ac-5-ASA steady-state AUC in both child/adolescent and adult populations for low-dose (A [5-ASA] and C $[$ Ac-5-ASA]) and high-dose exposures (B [5-ASA] and D [Ac-5-ASA]).

Abbreviations: 5-ASA, 5-aminosalicylic acid; Ac-5-ASA, acetyl-5-aminosalicylic acid; AUC $_{\mathrm{ss}}$, area under the curve for the defined interval between doses. 
Table 3 Treatment-emergent adverse events

\begin{tabular}{|c|c|c|c|c|}
\hline \multirow[t]{2}{*}{ TEAE } & \multicolumn{4}{|c|}{ Multimatrix mesalamine, $\mathbf{n}(\%)$} \\
\hline & $30 \mathrm{mg} / \mathrm{kg} / \mathrm{day}, \mathrm{n}=\mathbf{2} \mathrm{I}$ & $60 \mathrm{mg} / \mathrm{kg} / \mathrm{day}, \mathrm{n}=22$ & 100 mg/kg/day, n=9 & All doses, $\mathrm{N}=\mathbf{5 2}$ \\
\hline Subjects with $\geq I$ TEAE & $4(19.0)$ & $4(18.2)$ & $2(22.2)$ & $10(19.2)$ \\
\hline Gastrointestinal disorders & $2(9.5)$ & $2(9.1)$ & 0 & $4(7.7)$ \\
\hline Abdominal pain & I (4.8) & I (4.5) & 0 & $2(3.8)$ \\
\hline Musculoskeletal and connective tissue disorders & I (4.8) & I (4.5) & 0 & $2(3.8)$ \\
\hline Musculoskeletal pain & I (4.8) & I (4.5) & 0 & $2(3.8)$ \\
\hline Nervous system disorders & $2(9.5)$ & I (4.5) & 0 & $3(5.8)$ \\
\hline Headache & I (4.8) & I (4.5) & 0 & $2(3.8)$ \\
\hline
\end{tabular}

Abbreviation: TEAE, treatment-emergent adverse event.

\section{Discussion}

This is the first study to evaluate the safety and pharmacokinetics of multimatrix mesalamine in children and adolescents diagnosed with UC. Multimatrix mesalamine was generally safe and well tolerated. No fatal TEAEs, other serious TEAEs, or TEAEs leading to discontinuation of treatment occurred during the study, and the incidence of TEAEs was comparable between dose and age groups. Furthermore, the types and frequencies of clinical laboratory abnormalities and other safety parameters were low, and comparable between dose and age groups.

The pharmacokinetic profiles of 5-ASA and Ac-5-ASA at 30 or $60 \mathrm{mg} / \mathrm{kg}$ once daily were similar to those observed historically in adults after a 2,400 $\mathrm{mg}$ daily dose. ${ }^{15,16}$ Likewise, the pharmacokinetic profiles of 5-ASA and Ac-5-ASA at $100 \mathrm{mg} / \mathrm{kg}$ once daily were also similar to those in adults after a $4,800 \mathrm{mg}$ daily dose. ${ }^{15,16}$ These conclusions were based on the variable absorption profiles with initial and secondary peaks, the percentage of the 5-ASA absorbed, renal clearance of 5-ASA and Ac-5-ASA, plasma exposure $\left(\mathrm{AUC}_{\mathrm{ss}}\right.$ and $\mathrm{C}_{\text {max,ss }}$ ), and the inter-subject variability in pharmacokinetic parameters (Table 2). ${ }^{15,16}$ For example, in adults, the total absorption of 5-ASA from multimatrix mesalamine 2.4 or $4.8 \mathrm{~g}$ administered once daily for 14 days to healthy volunteers was approximately $21 \%-22 \%$ of the administered dose. ${ }^{15}$ In the current study, 5-ASA absorption ranged from $22 \%$ to $29 \%$ across doses.

The overall similarity in 5-ASA and Ac-5-ASA exposures between children/adolescents and adults suggests that the novel, smaller 300 and $600 \mathrm{mg}$ multimatrix mesalamine tablets developed for this study performed as intended, delivering 5-ASA to the colon in a similar fashion to the commercial $1,200 \mathrm{mg}$ multimatrix mesalamine tablets. Hence, these new 300 and $600 \mathrm{mg}$ tablets may be suitable for use in future studies.

For both 5-ASA and Ac-5-ASA, pharmacokinetic steady state was attained by day 5 for all doses, and systemic exposure of 5-ASA and Ac-5-ASA (measured by mean $\mathrm{AUC}_{\mathrm{ss}}$ and $\mathrm{C}_{\text {max,ss }}$ ) on day 7 increased in a dose-proportional manner between 30 and $60 \mathrm{mg} / \mathrm{kg} /$ day doses (Table 2). Mean $\mathrm{AUC}_{\mathrm{ss}}$ and $\mathrm{C}_{\text {max,ss }}$ increased subproportionally between 60 and $100 \mathrm{mg} / \mathrm{kg} /$ day doses, possibly due to the maximum dose restriction of $4,800 \mathrm{mg} /$ day, with the highest dose of $100 \mathrm{mg} / \mathrm{kg}$ only being administered to subjects weighing less than $50 \mathrm{~kg}$. In the $100 \mathrm{mg} / \mathrm{kg} /$ day dose group, a mean of $22.1 \%$ of the dose was absorbed (similar to the $21 \%-22 \%$ observed in adults),${ }^{15}$ whereas the corresponding values for the 30 and $60 \mathrm{mg} / \mathrm{kg}$ /day dose groups were higher $(29.4 \%$ and $27.0 \%$, respectively), suggesting that there also may be differences in the extent of absorption. Nevertheless, these assessments of dose-proportionality should be interpreted with caution due to the large inter-subject pharmacokinetic variability and the small sample size $(\mathrm{n}=9)$ receiving $100 \mathrm{mg} / \mathrm{kg} /$ day.

In addition to the typical non-compartmental pharmacokinetic analysis, a population pharmacokinetic model was developed to describe the pharmacokinetics of 5-ASA and Ac-5-ASA (Figure S1), and was subsequently used to simulate exposures in a broader population of children and adolescents with UC, following repeat oral administration of multimatrix mesalamine (Figures 3A-D; Tables S3 and S4). The variability in the predicted steady-state exposures for children and adolescents was similar to the observed variability in adults for both 5-ASA AUC (CV $\approx 50 \%$ in children and adolescents and 60\% in adults) and Ac-5-ASA AUC (CV $\approx 40 \%-45 \%$ in both populations). ${ }^{15,16}$ Additionally, absorption from two depots, as described in the final model, is consistent with the multimatrix mesalamine tablet, delivering an initial burst of 5-ASA that occurs from disintegration of the enteric coating, followed by leaching of 5-ASA out of the core as the tablet travels through the terminal ileum and colon. Therefore, the absorption data provide support for the drug being delivered in accordance with the design concept. Finally, results from the modeling and simulation in the current analysis suggest that the proposed dosing regimen for examining the safety and efficacy of multimatrix mesalamine in children and adolescents is likely to produce exposures to 5-ASA and Ac-5-ASA within 
the range of exposures at which safety and efficacy have been established in adults. As a result, these data supported the proposed doses for the Phase III safety and efficacy trial of multimatrix mesalamine in pediatric patients with UC (PACE; NCT02093663).

\section{Acknowledgments}

The authors would like to thank Richard Abbott and York Bioanalytical Solutions for excellent bioanalytical support, and Susi Inglis for statistical support. Research was funded by the sponsor, Shire Development LLC. Under the direction of the authors, Jason Jung, PhD, an employee of MedErgy, provided writing assistance for this manuscript. Editorial assistance in formatting, proofreading, copy editing, and fact checking was also provided by MedErgy. Representatives from Shire also reviewed and edited this manuscript for scientific accuracy. Shire Development LLC provided funding to MedErgy for support in writing and editing this manuscript.

\section{Author contributions}

Carmen Cuffari was involved with the study design as well as data analysis and interpretation. David Pierce was involved with study concept and design, oversight of the analysis, and interpretation of data (including oversight of pharmacokinetic details included in the manuscript). Bartosz Korczowski and Krzysztof Fyderek supervised the study conduct and were involved with data acquisition. Heather Van Heusen was involved with study concept and design; oversight of study conduct, execution, and data analyses; development of the clinical study report; and development of the protocol. Stuart Hossack was involved with non-compartmental pharmacokinetic data analysis and interpretation of data for the clinical study report. Hong Wan was involved with acquisition of data, analysis and interpretation of data, and statistical analysis. Alena YZ Edwards was involved with analysis and interpretation of data. Patrick Martin was involved with the overarching study concept, design, conduct, and reporting, and as the article guarantor, he takes responsibility for the integrity of the work as a whole, from inception to published article. All authors contributed to drafting of the manuscript or critical revision of the manuscript for important intellectual content, gave final approval of the version to be published, and agree to be accountable for all aspects of the work.

\section{Disclosure}

Carmen Cuffari served as a consultant for Shire, Prometheus, and Abbott Nutritionals. David Pierce is a former employee of Shire, and holds stock in Shire and in GlaxoSmithKline. Bartosz Korczowski and Krzysztof Fyderek received grants from Shire for the study research conducted. Heather Van Heusen, Hong Wan, and Patrick Martin are employees of Shire, and hold stock and/or stock options at Shire. Stuart Hossack is an employee of Covance Clinical Research Unit Limited, which received funding from Shire for assistance with data analysis. Alena YZ Edwards is an employee of ICON Early Phase Services, which received funding from Shire for assistance with data analysis.

\section{References}

1. Cosnes J, Gower-Rousseau C, Seksik P, Cortot A. Epidemiology and natural history of inflammatory bowel diseases. Gastroenterology. 2011; 140(6):1785-1794.

2. Irvine EJ. Quality of life of patients with ulcerative colitis: past, present, and future. Inflamm Bowel Dis. 2008;14(4):554-565.

3. Adams SM, Bornemann PH. Ulcerative colitis. Am Fam Physician. 2013;87(10):699-705.

4. Kugathasan S, Judd RH, Hoffmann RG, et al. Epidemiologic and clinical characteristics of children with newly diagnosed inflammatory bowel disease in Wisconsin: a statewide population-based study. $J$ Pediatr. 2003;143(4):525-531.

5. Kornbluth A, Sachar DB. Ulcerative colitis practice guidelines in adults: American College of Gastroenterology, Practice Parameters Committee. Am J Gastroenterol. 2010;105(3):501-523.

6. D'Haens G, Sandborn WJ, Barrett K, Hodgson I, Streck P. Once-daily MMX $^{\circledR}$ mesalamine for endoscopic maintenance of remission of ulcerative colitis. Am J Gastroenterol. 2012;107(7):1064-1077.

7. Kane S, Katz S, Jamal MM, et al. Strategies in maintenance for patients receiving long-term therapy (SIMPLE): a study of MMX mesalamine for the long-term maintenance of quiescent ulcerative colitis. Inflamm Bowel Dis. 2012;18(6):1026-1033.

8. Lichtenstein GR, Kamm MA, Sandborn WJ, Lyne A, Joseph RE. MMX mesalazine for the induction of remission of mild-to-moderately active ulcerative colitis: efficacy and tolerability in specific patient subpopulations. Aliment Pharmacol Ther. 2008;27(11): 1094-1102.

9. Sandborn WJ, Kamm MA, Lichtenstein GR, Lyne A, Butler T, Joseph RE. MMX Multi Matrix System mesalazine for the induction of remission in patients with mild-to-moderate ulcerative colitis: a combined analysis of two randomized, double-blind, placebo-controlled trials. Aliment Pharmacol Ther. 2007;26(2):205-215.

10. Sutherland L, Macdonald JK. Oral 5-aminosalicylic acid for induction of remission in ulcerative colitis. Cochrane Database Syst Rev. 2006; (2):CD000543.

11. Ford AC, Achkar JP, Khan KJ, et al. Efficacy of 5-aminosalicylates in ulcerative colitis: systematic review and meta-analysis. Am J Gastroenterol. 2011;106(4):601-616.

12. Zeisler B, Lerer T, Markowitz J, et al. Outcome following aminosalicylate therapy in children newly diagnosed with ulcerative colitis. J Pediatr Gastroenterol Nutr. 2013;56(1):12-18.

13. Quiros JA, Heyman MB, Pohl JF, et al. Safety, efficacy, and pharmacokinetics of balsalazide in pediatric patients with mild-to-moderate active ulcerative colitis: results of a randomized, double-blind study. J Pediatr Gastroenterol Nutr. 2009;49(5):571-579.

14. US Department of Health and Human Services, Food and Drug Administration, Center for Drug Evaluation and Research (CDER), Center for Veterinary Medicine (CVM). Guidance for Industry. Bioanalytical Method Validation; 2001.

15. LIALDA ${ }^{\circledR}$ (mesalamine) delayed-release tablets, for oral use [package insert]. Wayne, PA: Shire US Inc.; 2014. 
16. Shire Development Inc. Lialda (mesalamine) delayed release tablets clinical pharmacology biopharmaceutics review. Food and Drug Administration Web site. Available from: http://www.accessdata. fda.gov/drugsatfda_docs/nda/2007/022000s000TOC.cfm. Accessed June 19, 2014.

17. Beal SL, Sheiner LB, Boeckmann A, Bauer RJ. NONMEM User's Guides (1989-2009). Ellicott City, MD, USA: ICON Development Solutions; 2009.
18. Anderson BJ, Holford NH. Mechanism-based concepts of size and maturity in pharmacokinetics. Annu Rev Pharmacol Toxicol. 2008;48: 303-332. 


\section{Supplementary materials}

Table SI Assay performance of 5-ASA and Ac-5-ASA bioanalytical quality control samples in human plasma and urine

\begin{tabular}{|c|c|c|c|}
\hline & \multicolumn{3}{|c|}{ 5-ASA and Ac-5-ASA nominal concentration in plasma } \\
\hline & Low QC (1 $2.5 \mathrm{ng} / \mathrm{mL})$ & Mid QC $(2,500 \mathrm{ng} / \mathrm{mL})$ & High QC $(4,000 \mathrm{ng} / \mathrm{mL})$ \\
\hline \multicolumn{4}{|l|}{ 5-ASA } \\
\hline $\mathrm{CV}, \%$ & 7.6 & 5.3 & 5.0 \\
\hline Bias, \% & 0.0 & 1.6 & -0.8 \\
\hline \multicolumn{4}{|l|}{ Ac-5-ASA } \\
\hline $\mathrm{CV}, \%$ & 10.1 & 4.8 & 7.7 \\
\hline \multirow[t]{3}{*}{ Bias, \% } & 2.4 & 5.2 & 3.3 \\
\hline & \multicolumn{3}{|c|}{ 5-ASA and Ac-5-ASA nominal concentration in urine } \\
\hline & Low QC (15.0 $\mu \mathrm{g} / \mathrm{mL})$ & Mid QC $(400 \mu \mathrm{g} / \mathrm{mL})$ & High QC (800 $\mu \mathrm{g} / \mathrm{mL})$ \\
\hline \multicolumn{4}{|l|}{ 5-ASA } \\
\hline $\mathrm{CV}, \%$ & 6.7 & 11.7 & 8.2 \\
\hline Bias, \% & -1.3 & -5.5 & -4.0 \\
\hline \multicolumn{4}{|l|}{ Ac-5-ASA } \\
\hline$C V, \%$ & 10.2 & 9.0 & 7.6 \\
\hline Bias, \% & 4.0 & 1.0 & -1.4 \\
\hline
\end{tabular}

Abbreviations: Ac-5-ASA, acetyl-5-aminosalicylic acid; 5-ASA, 5-aminosalicylic acid; QC, quality control; CV, coefficient of variation.

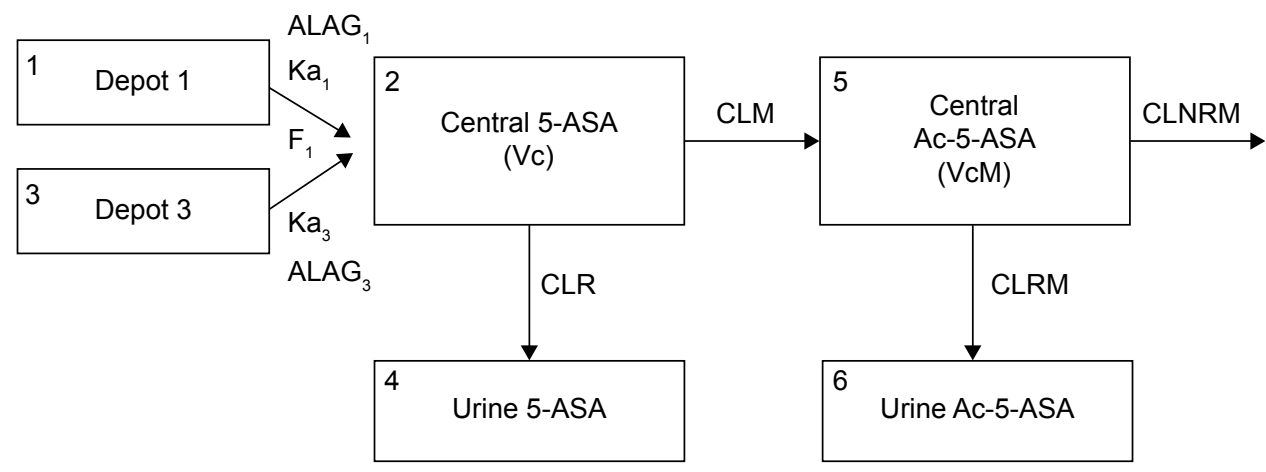

Figure SI Schematic of final population pharmacokinetic structural model.

Notes: Numbers on the top left-hand corner of the boxes represent the compartment numbers for the population pharmacokinetic model in the NONMEM code. Hence, the two depot compartments were denoted as depot I and depot 3.

Abbreviations: ALAG, absorption lag time from depot I; 5-ASA, 5-aminosalicylic acid; Ac-5-ASA, acetyl-5-aminosalicylic acid; Ka, absorption rate constant from depot I; $\mathrm{F}_{\mathrm{F}}$, fraction of dose absorbed from depot I; $\mathrm{Ka}_{3}$, absorption rate constant from depot 3; $\mathrm{ALAG}_{3}$, absorption lag time from depot 3 in addition to the lag time from depot I; CLM, metabolic clearance of 5-ASA; CLNRM, non-renal clearance of Ac-5-ASA; CLR, renal clearance of 5-ASA; CLRM, renal clearance of Ac-5-ASA. 
Table S2 Parameter estimates of final 5-ASA/Ac-5-ASA population pharmacokinetic model ${ }^{\text {a }}$

\begin{tabular}{|c|c|c|c|c|}
\hline \multirow[t]{2}{*}{ Parameter $^{\mathrm{b}}$} & \multicolumn{4}{|c|}{ NONMEM estimates } \\
\hline & Point estimate & \%RSE & $95 \% \mathrm{Cl}$ & CV\% \\
\hline CLR/F (L/h) & 1.15 & 45.9 & $1.01-1.32$ & NA \\
\hline $\mathrm{CLM} / \mathrm{F}(\mathrm{L} / \mathrm{h})$ & 85.6 & 1.38 & $75.9-96.5$ & NA \\
\hline $\mathrm{Vc} / \mathrm{F}(\mathrm{L})$ & 109 & 4.78 & $70.1-169$ & NA \\
\hline CLRM/F (L/h) & 2.54 & 6.34 & $2.27-2.86$ & NA \\
\hline CLNRM/F (L/h) & 74.4 & 1.31 & $66.7-83.1$ & NA \\
\hline $\mathrm{VcM} / \mathrm{F}(\mathrm{L})$ & 7.10 & 7.55 & $5.31-9.49$ & NA \\
\hline $\mathrm{Ka}_{1}\left(\mathrm{~h}^{-1}\right)$ & 0.0334 & 7.26 & $0.0207-0.0539$ & NA \\
\hline $\mathrm{Ka}_{3}\left(\mathrm{~h}^{-1}\right)$ & 0.273 & 19.5 & $0.165-0.448$ & NA \\
\hline $\mathrm{ALAG}_{1}(\mathrm{~h})$ & 5.10 & 5.34 & $4.31-6.05$ & NA \\
\hline $\mathrm{ALAG}_{3}(\mathrm{~h})$ & 15.0 & 1.23 & $14.0-16.1$ & NA \\
\hline $\mathrm{F}_{1}$ & 0.734 & 22.3 & $0.413-1.06$ & NA \\
\hline $\mathrm{CLR} / \mathrm{F} \sim \mathrm{WT}$ & $0.75 \mathrm{FIX}$ & NA & NA & NA \\
\hline $\mathrm{CLM} / \mathrm{F} \sim \mathrm{WT}$ & $0.75 \mathrm{FIX}$ & NA & NA & NA \\
\hline $\mathrm{Vc} / \mathrm{F} \sim \mathrm{WT}$ & I FIX & NA & NA & NA \\
\hline $\mathrm{CLRM} / \mathrm{F} \sim \mathrm{WT}$ & $0.75 \mathrm{FIX}$ & NA & NA & NA \\
\hline CLNRM/F WT & $0.75 \mathrm{FIX}$ & NA & NA & NA \\
\hline $\mathrm{VcM} / \mathrm{F} \sim \mathrm{WT}$ & I FIX & NA & NA & NA \\
\hline \multicolumn{5}{|c|}{ Inter-individual variability } \\
\hline$\omega_{\text {CLR }}^{2}$ & 0.181 & 22.8 & $0.100-0.262$ & $42.5^{c}$ \\
\hline$\omega_{C L M}^{2}$ & 0.115 & 25.4 & $0.0578-0.172$ & $33.9^{c}$ \\
\hline$\omega_{v_{c}}^{2}$ & 0.412 & 60.0 & $-0.0721-0.896$ & $64.2^{c}$ \\
\hline$\omega_{\text {CLRM }}^{2}$ & 0.133 & 21.6 & $0.0767-0.189$ & $36.5^{c}$ \\
\hline$\omega_{\text {CLNRM }}^{2}$ & 0.0823 & 27.0 & $0.0388-0.126$ & $28.7^{c}$ \\
\hline$\omega_{\mathrm{VCM}}^{2}$ & $0.0225 \mathrm{FIX}$ & NA & NA & $15.0^{c}$ \\
\hline$\omega_{\mathrm{Kal}}^{2}$ & 2.72 & 21.6 & $1.57-3.87$ & $165^{c}$ \\
\hline$\omega_{\mathrm{Ka} 3}^{2}$ & 1.87 & 27.3 & $0.868-2.87$ & $137^{c}$ \\
\hline$\omega_{\text {ALAGI }}^{2}$ & 0.256 & 23.0 & $0.14|-0.37|$ & $50.6^{c}$ \\
\hline$\omega_{\text {ALAG3 }}^{2}$ & $0.0225 \mathrm{FIX}$ & NA & NA & $15.0^{c}$ \\
\hline$\omega_{\mathrm{FI}}^{2}$ & 0.662 & 32.8 & $0.237-1.09$ & $81.4^{c}$ \\
\hline \multicolumn{5}{|l|}{ Residual variability } \\
\hline$\sigma_{\text {prop, plasma 5-ASA }}^{2}$ & 0.136 & 7.65 & $0.116-0.156$ & $36.9^{d}$ \\
\hline$\sigma_{\text {prop, urine 5-ASA }}^{2}$ & $0.00360 \mathrm{FIX}$ & NA & NA & $6.00^{d}$ \\
\hline$\sigma_{\text {prop, plasma Ac-5-ASA }}^{2}$ & 0.0829 & 7.45 & $0.0708-0.0950$ & $28.8^{d}$ \\
\hline$\sigma_{\text {prop, urine Ac-5-ASA }}^{2}$ & $0.00360 \mathrm{FIX}$ & NA & NA & $6.00^{d}$ \\
\hline
\end{tabular}

Notes: ${ }^{\mathrm{T}}$ The reference population for the pharmacokinetic parameters CLR/F, CLM/F, $\mathrm{Vc} / \mathrm{F}, \mathrm{CLRM} / \mathrm{F}, \mathrm{CLNRM/F}$, and $\mathrm{VcM} / \mathrm{F}$ is an individual weighing $70 \mathrm{~kg}$. ${ }^{\mathrm{b}} \mathrm{Estimates}$ and $95 \% \mathrm{Cl}$ back-transformed from $\log _{\mathrm{e}}$ scale. ${ }^{c} \mathrm{CV}_{T V_{\mathrm{p}}}=\sqrt{\mathrm{e}^{\omega_{\mathrm{p}}^{2}}-1}$, when $\omega_{\mathrm{p}}^{2}$ exceeds $0.15 .{ }^{\mathrm{d}} \mathrm{CV}$ of proportional error $\left(=\left[\sigma_{\text {prop }}^{2}{ }^{0.5} \times 100\right)\right.$.

Abbreviations: 5-ASA, 5-aminosalicylic acid; Ac-5-ASA, acetyl-5-aminosalicylic acid; ALAG, absorption lag time from depot I; ALAG 3 , absorption lag time from depot 3 in addition to the lag time from depot I; Cl, 95\% confidence interval on the parameter; CLM/F, apparent metabolic clearance of 5-ASA; CLNRM/F, apparent non-renal clearance of Ac-5-ASA; CLR/F, apparent renal clearance of 5-ASA; CLRM/F, apparent renal clearance of Ac-5-ASA; CV, coefficient of variation; $F_{1}$, fraction of dose absorbed from depot I; FIX, fixed; Ka, absorption rate constant from depot I; Ka absorption rate constant from depot 3; NA, not applicable; \%RSE, percent relative standard error of the estimate $=$ standard error/parameter estimate $\times 100 ; \mathrm{Vc} / \mathrm{F}$, apparent volume of central compartment of 5-ASA; $\mathrm{VcM} / \mathrm{F}$, apparent volume of central compartment of Ac-5-ASA; WT, body weight; $\omega_{C \mathrm{CR}}^{2}$, variance of random effect of $C L R / F ; \omega_{C I M}^{2}$, variance of random effect of $C L M / F ; \omega_{v_{v}}^{2}$, variance of random effect of $V_{C} / F$; $\omega_{C L R M}^{2}$, variance of random effect of CLRM/F; $\omega_{\text {CLNRM, }}^{2}$, variance of random effect of CLNRM/F; $\omega_{\mathrm{VCM}}^{2}$, variance of random effect of $\mathrm{VCM} / \mathrm{F} ; \omega_{\mathrm{Ka}}^{2}$, variance of random effect of Ka $; \omega_{\mathrm{Ka}}^{2}$, variance of random effect of $\mathrm{Ka}_{3} ; \omega_{\mathrm{ALAG}}^{2}$, variance of random effect of $\mathrm{ALAG}_{1} ; \omega_{\mathrm{ALAG} 3}^{2}$, variance of random effect of $\mathrm{ALAG}_{3} ; \omega_{\mathrm{FF}}^{2}$, variance of random effect of $\mathrm{F}_{1} ; \sigma_{\text {prop }}^{2}$, proportional component of the residual error model. 

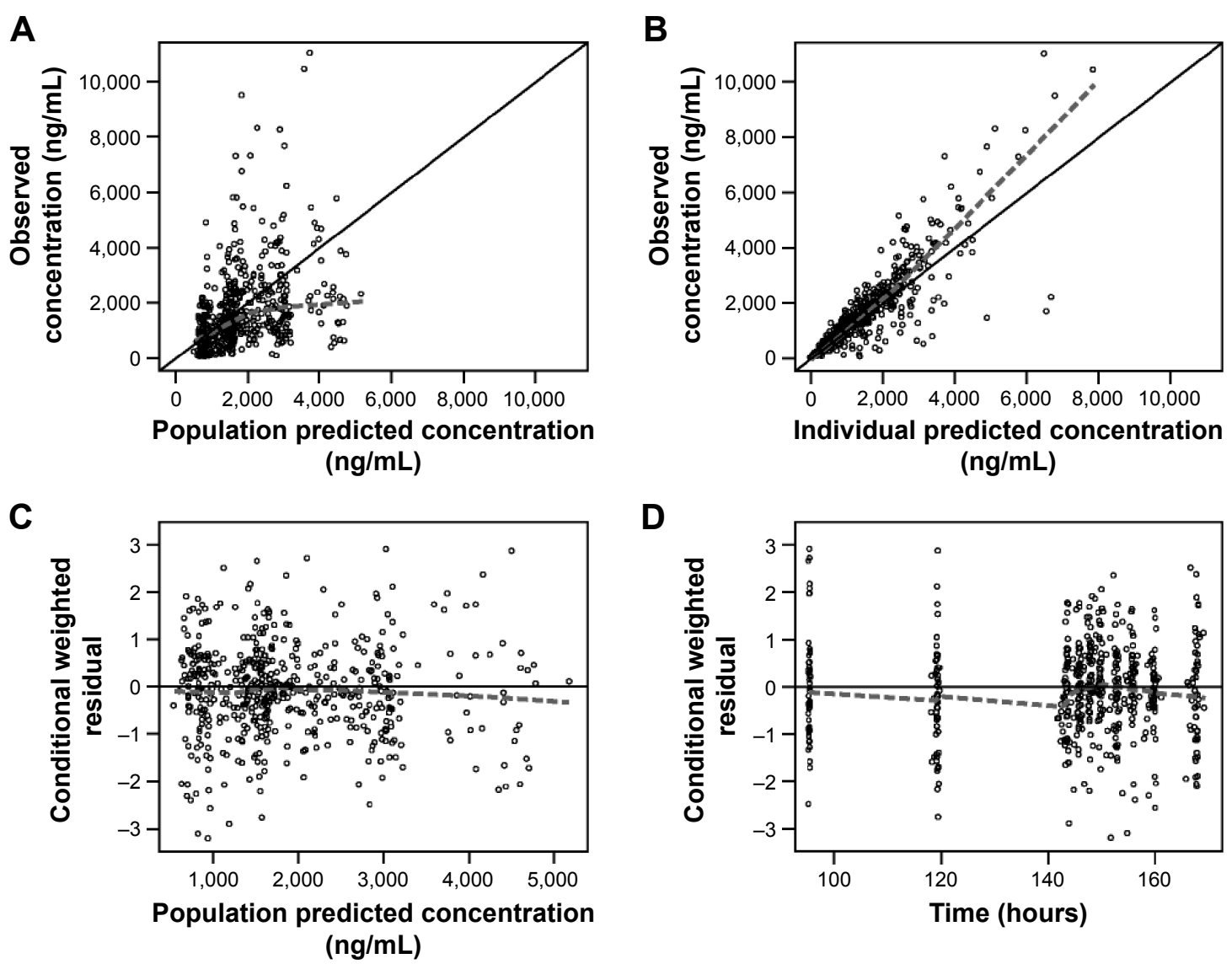

Figure S2 Goodness-of-fit and diagnostic plots for the final model in children and adolescents: plasma 5-ASA.

Notes: The dashed line represents the local regression (Loess) smoothing line. (A) Observed versus population predicted concentration; (B) observed versus individual predicted concentration; (C) conditional weighted residual versus population predicted concentration; (D) conditional weighted residual versus time.

Abbreviation: 5-ASA, 5-aminosalicylic acid. 
A

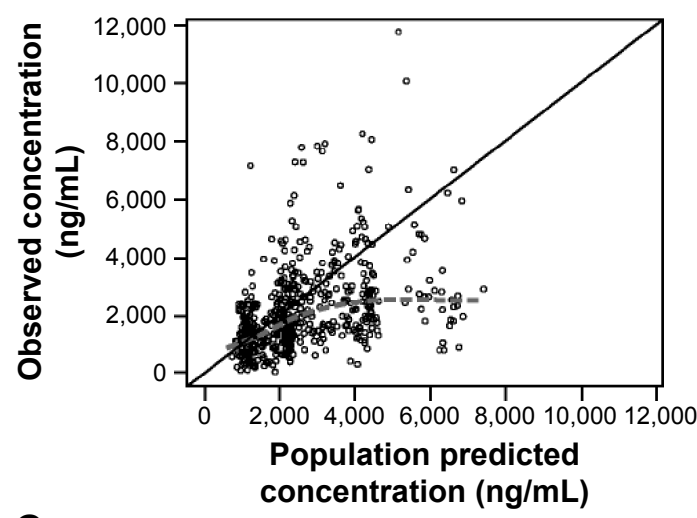

C

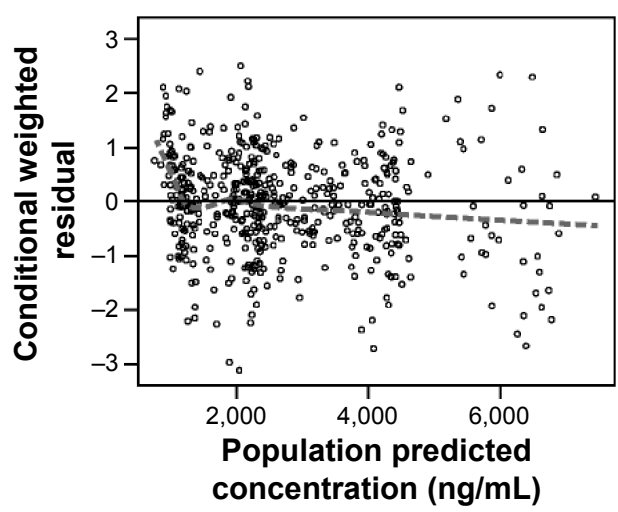

B

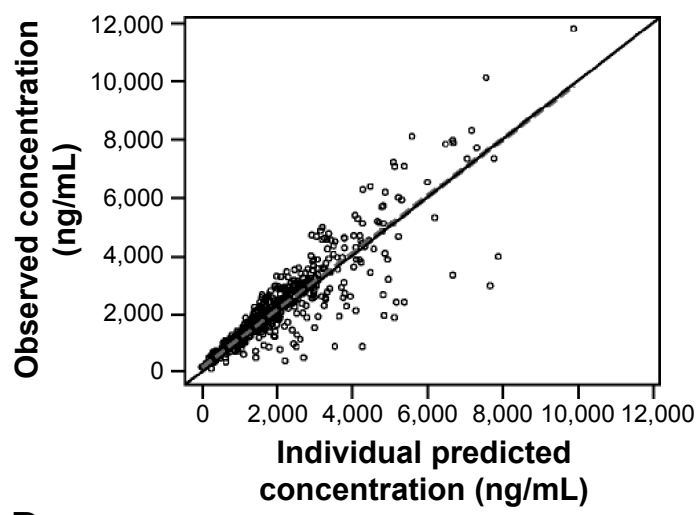

D

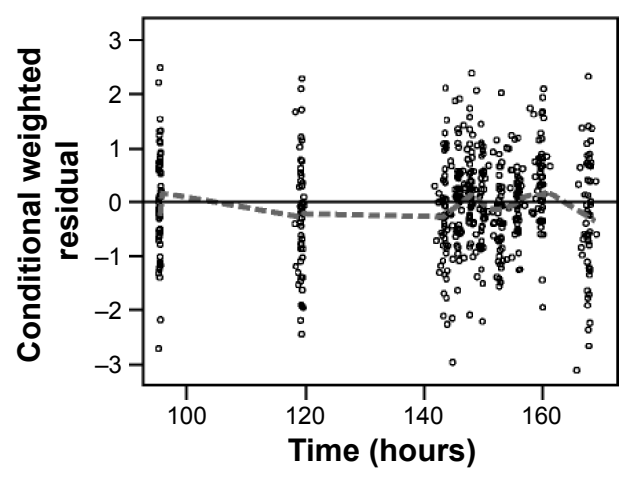

Figure S3 Goodness-of-fit and diagnostic plots for the final model in children and adolescents: plasma Ac-5-ASA.

Notes: The dashed line represents the local regression (Loess) smoothing line. (A) Observed versus population predicted concentration; (B) observed versus individual predicted concentration; (C) conditional weighted residual versus population predicted concentration; (D) conditional weighted residual versus time.

Abbreviation: Ac-5-ASA, acetyl-5-aminosalicylic acid.

Table S3 Simulated steady-state 5-ASA exposures by weight and dose group

\begin{tabular}{|c|c|c|c|}
\hline \multirow[t]{2}{*}{ Weight group } & \multirow[t]{2}{*}{ Statistic } & \multicolumn{2}{|l|}{ AUC (ng×h/mL) } \\
\hline & & Low dose & High dose \\
\hline \multirow[t]{5}{*}{$18-23$ kg (n=555) } & Dose (mg) & 900 & 1,800 \\
\hline & Mean & 24,100 & 47,000 \\
\hline & SD & 12,200 & 23,500 \\
\hline & $\mathrm{CV} \%$ & 50.6 & 50.0 \\
\hline & Median $(95 \% \mathrm{PI})^{\mathrm{a}}$ & $22,100(906-96,900)$ & $43,100(3,880-249,000)$ \\
\hline \multirow{5}{*}{$24-35$ kg ( $n=849)$} & Dose (mg) & 1,200 & 2,400 \\
\hline & Mean & 24,600 & 49,600 \\
\hline & SD & 12,200 & 24,800 \\
\hline & $\mathrm{CV} \%$ & 49.7 & 50.0 \\
\hline & Median $(95 \% \mathrm{PI})^{\mathrm{a}}$ & $22,800(652-|7|, 000)$ & $45,700(676-218,000)$ \\
\hline \multirow[t]{5}{*}{$36-50$ kg ( $n=962)$} & Dose (mg) & $\mathrm{I}, 800$ & 3,600 \\
\hline & Mean & 27,000 & 54,000 \\
\hline & SD & 13,100 & 26,500 \\
\hline & CV\% & 48.3 & 49.1 \\
\hline & Median $(95 \% \mathrm{PI})^{\mathrm{a}}$ & $25,000(36|-| 20,000)$ & $50,000(8 \mid 2-263,000)$ \\
\hline \multirow[t]{5}{*}{$5 \mathrm{I}-90 \mathrm{~kg}(\mathrm{n}=\mathrm{I}, 354)$} & Dose (mg) & 2,400 & 4,800 \\
\hline & Mean & 29,700 & 59,700 \\
\hline & SD & 14,300 & 28,400 \\
\hline & $\mathrm{CV} \%$ & 48.2 & 47.5 \\
\hline & Median $(95 \% \mathrm{PI})^{\mathrm{a}}$ & $27,500(620-125,000)$ & $55,500(1,030-363,000)$ \\
\hline \multirow[t]{5}{*}{ Adults ( $\mathrm{n}=28$ for $2,400 \mathrm{mg} ; \mathrm{n}=8 \mathrm{I}$ for $4,800 \mathrm{mg}$ ) } & Dose (mg) & 2,400 & 4,800 \\
\hline & Mean & 22,300 & 39,900 \\
\hline & SD & 13,700 & 24,400 \\
\hline & $\mathrm{CV} \%$ & 61.4 & 61.2 \\
\hline & Median $(95 \% \mathrm{PI})^{\mathrm{a}}$ & $16,900(7,160-57,800)$ & $36,800(1,030-103,000)$ \\
\hline
\end{tabular}

Note: aSummarized as median (2.5th percentile, 97.5th percentile).

Abbreviations: 5-ASA, 5-aminosalicylic acid; AUC, area under the curve; SD, standard deviation; CV, coefficient of variation; PI, percentile. 
Table S4 Simulated steady-state Ac-5-ASA pharmacokinetic parameters by dose and age group

\begin{tabular}{|c|c|c|c|}
\hline \multirow[t]{2}{*}{ Weight group } & \multirow[t]{2}{*}{ Statistic } & \multicolumn{2}{|l|}{ AUC (ng×h/mL) } \\
\hline & & Low dose & High dose \\
\hline \multirow[t]{5}{*}{$18-23$ kg (n=555) } & Dose (mg) & 900 & $\mathrm{I}, 800$ \\
\hline & Mean & 33,000 & 66,500 \\
\hline & SD & 13,900 & 28,400 \\
\hline & $\mathrm{CV} \%$ & 42.1 & 42.7 \\
\hline & Median $(95 \% \mathrm{PI})^{\mathrm{a}}$ & $30,800(2,290-114,000)$ & $63,100(8,440-199,000)$ \\
\hline \multirow[t]{5}{*}{$24-35 \mathrm{~kg}(\mathrm{n}=849)$} & Dose (mg) & 1,200 & 2,400 \\
\hline & Mean & 34,200 & 68,300 \\
\hline & SD & 15,000 & 30,500 \\
\hline & $\mathrm{CV} \%$ & 43.9 & 44.6 \\
\hline & Median $(95 \% \mathrm{PI})^{\mathrm{a}}$ & $32,400(1,510-229,000)$ & $64,700(1,330-432,000)$ \\
\hline \multirow[t]{5}{*}{$36-50 \mathrm{~kg}(\mathrm{n}=962)$} & Dose (mg) & 1,800 & 3,600 \\
\hline & Mean & 37,800 & 75,200 \\
\hline & SD & 16,000 & 31,800 \\
\hline & $\mathrm{CV} \%$ & 42.5 & 42.3 \\
\hline & Median $(95 \% \mathrm{PI})^{\mathrm{a}}$ & $35,700(684-225,000)$ & $71,600(1,760-383,000)$ \\
\hline \multirow[t]{5}{*}{$5 I-90 \mathrm{~kg}(\mathrm{n}=1,354)$} & Dose (mg) & 2,400 & 4,800 \\
\hline & Mean & 41,200 & 82,900 \\
\hline & SD & 17,300 & 34,300 \\
\hline & $\mathrm{CV} \%$ & 41.8 & 41.4 \\
\hline & Median $(95 \% \mathrm{PI})^{\mathrm{a}}$ & $39,200(800-182,000)$ & $78,900(2,850-343,000)$ \\
\hline \multirow[t]{5}{*}{ Adults ( $\mathrm{n}=28$ for $2,400 \mathrm{mg} ; \mathrm{n}=8$ I for $4,800 \mathrm{mg}$ ) } & Dose (mg) & 2,400 & 4,800 \\
\hline & Mean & 41,300 & 60,800 \\
\hline & SD & 16,100 & 27,100 \\
\hline & $\mathrm{CV} \%$ & 39.0 & 44.7 \\
\hline & Median $(95 \% \mathrm{PI})^{\mathrm{a}}$ & $38,200(16,400-75,400)$ & $59,700(5,330-123,000)$ \\
\hline
\end{tabular}

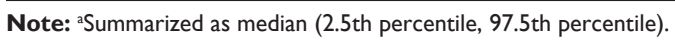

Abbreviations: Ac-5-ASA, acetyl-5-aminosalicylic acid; AUC, area under the curve; SD, standard deviation; CV, coefficient of variation; PI, percentile.

\section{Publish your work in this journal}

Drug Design, Development and Therapy is an international, peerreviewed open-access journal that spans the spectrum of drug design and development through to clinical applications. Clinical outcomes, patient safety, and programs for the development and effective, safe, and sustained use of medicines are a feature of the journal, which has also been accepted for indexing on PubMed Central. The manuscript management system is completely online and includes a very quick and fair peer-review system, which is all easy to use. Visit http://www.dovepress.com/testimonials.php to read real quotes from published authors.

Submit your manuscript here: http://www.dovepress.com/drug-design-development-and-therapy-journal 